DOI 10.37882/2223-2982.2020.04.30

\title{
ФОРМИРОВАНИЕ И КОРРЕКЦИЯ САМООЦЕНКИ ЛИЧНОСТИ ОБУЧАЮЩИХСЯ В СПЕЦИАЛЬНОЙ МЕДИЦИНСКОЙ ГРУППЕ В ПРОЦЕССЕ ЗАНЯТИЙ ФИЗИЧЕСКОЙ КУЛЬТУРОЙ В TЕХНИЧЕСКОМ ВУЗЕ
}

\author{
Соколова Ирина Юрьевна \\ старший преподаватель, ФГБОУ «Вологодский \\ государственный университет» \\ irinasokolova07@mail.ru \\ Филь Валерия Владиславовна \\ старший преподаватель, ФГБОУ «Вологодский \\ государственный университет» \\ lerikafil@mail.ru \\ Лебедева Евгения Геннадьевна \\ доцент, ФГБОУ «Вологодский государственный \\ университет»

\section{jenya1433@yandex.ru \\ Орехова Ирина Вячеславовна \\ старший преподаватель, ФГБОУ «Вологодский государственный университет» oreshok.irina@yandex.ru}

E. Lebedeva

I. Orekhova

Summary: This work deals with the educational process of physical culture in the University, which in certain pedagogical conditions affects the formation and correction of adequate self-assessment of the personality of students, as well as its positive impact on the comprehensive development of all physical qualities and correction of minor disorders of the musculoskeletal system.

Keywords: The self-assessment correction, personality, students, physical culture, special medical group, exercises.
Аннотация: В данной работе рассматривается учебно-воспитательный процесс по физической культуре в ВУЗе, который в определенных педагогических условиях оказывает влияние на формирование и коррекцию адекватной самооценки личности обучающихся, так же его положительное влияние на комплексное развитие всех физических качеств и исправление незначительных нарушений опорно-двигательного аппарата.

Ключевые слова: коррекция, личность, обучающиеся, физическая культура, специальная медицинская группа, упражнения.

\section{Актуальность.}

$\mathrm{B}$ настоящее время в нынешнем обществе происходят значительные преобразования во всех сферах жизни. Именно поэтому в современной педагогической науке всё больший интерес вызывает особенность становления личности человека, который может динамично и, главное, адекватно общаться с окружающим миром. Стоит отметить, что в текущем состоянии, в котором находится высшая школа, имеются некоторые противоречия между процессами развития личности и традиционной системой высшего вузовского образования.

В нашей стране одним из основных средств воспитания личности человека стала физическая культура, поскольку она сочетает в себе как внутреннее богатство и нравственную чистоту, так и физическое совершенство. Эта дисциплина для студентов вузов включена в базовую (обязательную) часть и является завершающим этапом непрерывного и организованного процесса формиро- вания физической культуры личности. Мы согласны с мнением коллег Лебедевой Е.Г. и Куликовой М.Г., что «формирование потребности в физическом и психическом здоровье является основной задачей в физическом воспитании студентов. Чтобы этот процесс формирования потребности был эффективным, он должен быть осознанным» [9, стр. 64]. Состояние физической культуры и спорта в современном высшем учебном заведении требует увеличения эффективности, а так же поиска новых форм, методов, средств, нестандартного подхода к организации всего учебно-воспитательного процесса в зависимости от физического состояния обучающихся. Новые требования обусловлены целым рядом причин, и в первую очередь это значительное ослабление здоровья молодого поколения.

\section{Методы и организация исслеАования}

Наши исследования были проведены на базе Вологодского государственного университета. В исследовании принимало участие 184 обучающихся институтов 
с технической направленностью. В дальнейшем были организованы две группы обучающихся по дисциплине «Физическая культура и спорт» и «Элективные дисциплины по физической культуре и спорту» по состоянию здоровья, относящиеся к специальной медицинской группе (далее СМГ). Изначально группы отличались однородностью результатов и с примерно одинаковыми заболеваниями (связанными с незначительными нарушениями ОДА) и схожими антропометрическими данными.

Группы сформированы из обучающихся разных академических групп, страдающих незначительными отклонениями в состоянии здоровья и психологически не готовых к занятиям физической культурой в основной группе.

Контрольная группа (КГр) занималась по программе государственного образовательного стандарта высшего профессионального образования второго поколения. В экспериментальной группе (ЭГр) непосредственно сами обучающиеся, принимали активное участие в процессе развивающего эксперимента, а так же в оценивании промежуточных результатов.

Программа занятий, созданная нами, строилась на основе воплощения конкретных педагогических условий в учебно-воспитательный процесс и заключалась в определении эффективности разрозненного воздействия на физическое состояние обучающихся СМГ в структуре учебных занятий по дисциплинам «физическая культура и спорт» и «элективные дисциплины по физической культуре и спорту».

Применялись различные упражнения из направлений пилатеса, йоги, стрейтчинга и танцевального направления ZUMBA. Занятия включали упражнения у шведской стенки, с гимнастическими палками, с набивными мячами разного веса, мягкими гантелями, фитболами, упражнения на растягивание; занятия на тренажерах - для формирования и укрепления мышечного корсета (в исходном положении - лежа на спине, а так же в положении полулежа на спине, чтобы не допустить малейшее негативное воздействие на позвоночник; а после окончания занятия - обязательно упражнения на вытягивание на шведской стенке). Большое количество упражнения проводится в исходном положении - лежа, сидя, на четвереньках. Проводились дыхательные упражнения, которые выполнялись на каждом занятии. Полностью исключались упражнения с отягощениями в исходном положении стоя, прыжки и различные подскоки. В занятие включались элементы спортивных игр (или подвижные игры), дыхательные и общеразвивающие упражнения, ходьба, ходьба в приседе, скандинавская ходьба.

Помимо образовательных и оздоровительных задач на занятиях решаются и задачи воспитательные. Средствами физической культуры воспитываются настойчивость и смелость, дисциплинированность и навыки культурного поведения, чувство дружбы, товарищества и взаимопомощи.

Обучающиеся независимо от преподавателя контролировали и оценивали свои двигательные действия, а также аргументировали, за что именно поставили себе ту или иную отметку. Постоянно вели дневник самоконтроля, который позволил в дальнейшем более точно обработать полученные данные. Всю предоставленную информацию обучающихся и полученные результаты были подвергнуты анализу самим преподавателем. Проводились систематический разбор своих занятий и регулярный отчет непосредственно перед преподавателем $[5,10,11]$.

Чтобы проверять правильность распределения нагрузки во время учебного занятия, обучающиеся самостоятельно измеряют частоту сердечных сокращений, путем измерения пульса, по сигналу преподавателя вычисляют в течение 15 секунд. Такого рода подсчет обычно производится 4 раза: до начала занятия (в состоянии покоя), в середине - после наиболее утомительного упражнения основной части (в первые 15 сек.), непосредственно сразу после окончания занятия и через 5 мин. периода восстановления.

\section{Экспериментальная часть}

Во время планирования учебной нагрузки необходимо отталкиваться от того, что осуществляемые тренировочные упражнения, одной и те же величины, не приводят к значительным морфофункциональным изменениям, так как организм частично приспосабливается и впоследствии полностью адаптируется к предлагаемым физическим нагрузкам. Поэтому наши занятия мы выстраивали с систематически постепенным повышением физической нагрузки. Поскольку прогрессирующее увеличение на определенных стадиях входит в разногласие с ходом адаптивных изменений, то в ее основу был положен волнообразно-восходящий принцип. Такое постепенное изменение физических нагрузок в учебно-воспитательном процессе, дает возможность избежать разногласия между видами работы разной направленности, интенсивностью и объемом, а так же процессами утомления и восстановления. Довольно эффективной формой организации учебного процесса всегда считалась комплексная форма. Она одновременно позволяет решать целый ряд задач. Одной из таких задач, является вариативность использования нагрузки, методов и средств, что обеспечивает всестороннее развитие качеств, определяющих уровень достижений, а так же повышению работоспособности при выполнении отдельных движений. Такая форма проведения занятий позволяет гораздо быстрее вовлечь обучающегося в учебный процесс. Именно данные факторы и обусловили выбор комплексной формы занятий со студентами СМГ $[1,3]$. 
Огромное значение у обучающихся имеет формирование адекватной самооценки личности и здоровья в процессе занятий физической культурой в ВУЗе. Умение объективно и адекватно оценивать свои физические возможности во время выполнения конкретных двигательных действий, а так же соотносить достигнутые результаты с требованиями, которым они должны отвечать. Это условие является необходимым для полноценного усвоения обучающимися содержания рабочих учебных программы по дисциплинам «физическая культура и спорт» и «элективные дисциплины по физической культуре и спорту». Тем не менее, самооценка личности является тем фактором, который проявляется в процессе развития самосознания, и в значительной степени может завесить от различных объективных условий [5].

Как выяснилось во время эксперимента, в условиях обычного занятия по физической культуре обучающиеся СМГ не могут проанализировать свои различные двигательные действия и выделить четкие критерии их оценки. Они в основном сводят анализ результатов своих двигательных действий к количественному показателю учебных тестов.

Оригинальность самооценки обучающихся СМГ заключалось в нахождении рассогласованности между самооценкой личности и оценкой своих возможностей в различных видах деятельности. Этот факт объяснялся тем, что различные стороны самооценки обучающихся находятся на разных этапах формирования и характеризуются различной степенью реалистичности.

Для полноценного освоения программы по дисциплине «Физическая культура и спорт», и «Элективные дисциплины по физической культуре и спорту», обучающимся, при выполнении различных упражнений, необходимо независимо и объективно оценивать свои двигательные умения и навыки, которые они приобретают во время учебного - воспитательного процесса. Кроме этого они должны грамотно соотносить достигнутые результаты с требованиями, которым они должны отвечать.

Известно, что под влиянием физической нагрузки и при применении одних и тех же средств и методов функциональные изменения, которые положительно влияют на организм, формируются примерно через месяц после начала занятий.

Рекомендации по содержанию, объему и организации тренировочных занятий строились нами в соответствии с данными научно-методической литературы и собственных исследований, проводимых ранее самостоятельно и в коллективе с коллегами $[2,4,6,7,8]$.

\section{Результаты и их обсужление}

Контроль процесса физического воспитания в ВоГУ включал в себя не только данные регистрации и оценку показателей общего физического состояния обучающихся, но и их самооценку. Все данные заносились в дневник самоконтроля. Как показали наши исследования после проведенного эксперимента, результаты обучающихся ЭГр по многим показателям имеют достоверно более высокие уровни, по сравнению с их ровесниками из КГр.

Данные соматоскопии на этапе эксперимента свидетельствуют о том, что у обследуемых обучающихся СМГ при осмотре отмечено анфас расположение надплечий на одном горизонтальном уровне, левый треугольник талии незначительно уступает правому.

Расстояние от 7 шейного позвонка до нижнего угла лопаток с обеих сторон в ЭГр стало почти одинаковым и составляет в среднем 14,12 см, в КГр справа 14,49 и 13,68 слева. Данные результаты свидетельствуют о наличии положительной динамики в осанке ЭГр, которая приближается к физиологически правильной и имеет достоверные различия $(\mathrm{P}<0,05)$. Анализ динамики прироста показателя внутри каждой группы показал, что у обучающихся ЭГр и КГр результат достоверно улучшился $(\mathrm{P}<0,05)$.

В блоке функциональных возможностей организма достоверные различия были зафиксированы между обучающимися ЭГр и КГр по пяти показателям. Такие как время восстановления пульса после нагрузки, подвижность позвоночника влево, вправо, вперед и сила мышц спины $(\mathrm{P}<0,05)$.

Так же отмечались достоверные различия в блоке самооценки здоровья. Были зафиксированы изменения по показателю- общее физическое состояние обучающихся СМГ, которые характеризовались отсутствием частых болей и прочих неприятных ощущений, ограничений в движениях и перемещении. Внутри обеих групп достоверные отличия отмечены по одному очень значимому показателю, такому как общее физическое состояние.

В блоке самооценки личности у обучающихся ЭГр и КГр за время эксперимента достоверные различия тоже были зафиксированы $(P<0,05)$ по трем тестам. Реактивная и личностная тревожность, самооценка личности. Внутри ЭрГ достоверные различия $(P<0,01)$ отмечены по двум показателям - реактивная и личностная тревожность. В КГр обучающихся после эксперимента достоверных изменений не обнаружено.

Анализ полученных нами результатов тестирования обучающихся СМГ позволил выделить три группы с определенным уровнем (заниженный, адекватный и завышенный) развития самооценки личности в процессе занятий физической культурой в вузе.

После эксперимента в блоке самооценки здоровья и исследования уровней каждого теста показало следующие результаты (Таблица 1). 
Таблица 1

\begin{tabular}{|l|l|l|l|l|}
\hline & \multicolumn{2}{|c|}{ Контрольная группа } & \multicolumn{2}{|c|}{ Экспериментальная группа } \\
\hline & До начала эксперимента & $\begin{array}{l}\text { После окончания } \\
\text { эксперимента }\end{array}$ & До начала эксперимента & $\begin{array}{l}\text { После окончания } \\
\text { эксперимента }\end{array}$ \\
\hline Заниженный уровень & $39,6 \%$ & $33,9 \%$ & $39,7 \%$ & $15,4 \%$, \\
\hline Адекватный уровень & $48,01 \%$ & $50,9 \%$, & $48,4 \%$ & $63,6 \%$ \\
\hline Завышенный уровень & $12,39 \%$ & $15,2 \%$ & $11,9 \%$ & $21,0 \%$ \\
\hline
\end{tabular}

Таблица 2

\begin{tabular}{|l|l|l|l|l|}
\hline & \multicolumn{2}{|c|}{ Контрольная группа } & \multicolumn{2}{c|}{ Экспериментальная группа } \\
\hline & До начала эксперимента & $\begin{array}{l}\text { После окончания } \\
\text { эксперимента }\end{array}$ & До начала эксперимента & $\begin{array}{l}\text { После окончания } \\
\text { эксперимента }\end{array}$ \\
\hline Заниженный уровень & $26,14 \%$, & $24,02 \%$ & $26,9 \%$ & $14,9 \%$ \\
\hline Адекватный уровень & $57,94 \%$ & $56,48 \%$ & $54,58 \%$ & $67,89 \%$ \\
\hline Завышенный уровень & $15,92 \%$ & $19,5 \%$ & 18,52 & $17,21 \%$ \\
\hline
\end{tabular}

Таблица 3

\begin{tabular}{|l|l|l|l|l|}
\hline & \multicolumn{2}{|c|}{ Контрольная группа } & \multicolumn{2}{c|}{ Экспериментальная группа } \\
\hline & До начала эксперимента & $\begin{array}{l}\text { После окончания } \\
\text { эксперимента }\end{array}$ & До начала эксперимента & $\begin{array}{l}\text { После окончания } \\
\text { эксперимента }\end{array}$ \\
\hline Заниженный уровень & $12,3 \%$ & $9,4 \%$ & $16,0 \%$ & $7,0 \%$ \\
\hline Адекватный уровень & $62,9 \%$ & $64,7 \%$ & $58,1 \%$ & $83,1 \%$ \\
\hline Завышенный уровень & $24,8 \%$ & $25,9 \%$ & $25,9 \%$ & $9,9 \%$ \\
\hline
\end{tabular}

Таблица 4

\begin{tabular}{|l|l|l|l|l|}
\hline & \multicolumn{2}{|c|}{ Контрольная группа } & \multicolumn{2}{|c|}{ Экспериментальная группа } \\
\hline & До начала эксперимента & $\begin{array}{l}\text { После окончания } \\
\text { эксперимента }\end{array}$ & До начала эксперимента & $\begin{array}{l}\text { После окончания } \\
\text { эксперимента }\end{array}$ \\
\hline Заниженный уровень & $26,2 \%$ & $21,3 \%$ & $22,2 \%$ & $20,1 \%$ \\
\hline Адекватный уровень & $50,8 \%$ & $60,8 \%$ & $60,9 \%$ & $72,0 \%$ \\
\hline Завышенный уровень & $23,0 \%$ & $17,9 \%$ & $16,9 \%$ & $7,9 \%$ \\
\hline
\end{tabular}

Таблица 5

\begin{tabular}{|l|l|l|l|l|}
\hline & \multicolumn{2}{|c|}{ Контрольная группа } & \multicolumn{2}{|c|}{ Экспериментальная группа } \\
\hline & До начала эксперимента & $\begin{array}{l}\text { После окончания } \\
\text { эксперимента }\end{array}$ & До начала эксперимента & $\begin{array}{l}\text { После окончания } \\
\text { эксперимента }\end{array}$ \\
\hline Заниженный уровень & $51,0 \%$ & $42,8 \%$ & $51,9 \%$ & $17,3 \%$ \\
\hline Адекватный уровень & $36,8 \%$ & $49,0 \%$ & $35,1 \%$ & $70,8 \%$ \\
\hline Завышенный уровень & $12,2 \%$ & $8,2 \%$ & $13 \%$ & $11,9 \%$ \\
\hline
\end{tabular}


Как видим, до начала эксперимента менее половины испытуемых в обеих группах имеют адекватный уровень, а $39 \%$ имеют заниженный, а 12 - завышенный уровни. Но после окончания эксперимента ситуация несколько меняется. Если в контрольной группе ситуация меняется не сильно резко (прирост адекватного и завышенного уровней 2-3\%), то в экспериментальной группе происходят существенные сдвиги. Прирост адекватного уровня составляет $15 \%$, завышенного - 9,9\%, а доля обучающихся с заниженным уровнем снижается более чем в 2 раза и составляет $15,4 \%$.

Результаты, полученные по показателю самооценки здоровья, воздействующим на достижение благополучия в семье, учебе, в общении с друзьями представлены в таблице № 2 .

Как и в предыдущем случае, исходные данные практически равные. До начала эксперимента чуть более половины испытуемых в обеих группах имеют адекватный уровень, а 26 \% имеют заниженный, а 15 и $18 \%$ - завышенный уровни. Если в контрольной группе существенных изменений не наблюдается, то в экспериментальной группе ситуация совершенно иная. Резко возрастает количество обучающихся с адекватным уровнем и составляет 2/3 всех испытуемых, стоит отметить снижение количества обучающихся с заниженным уровнем в 2 раза, однако на 1,3 \% снизилось количество обучающихся с завышенным уровнем.

Исследование уровней самооценки тревожности в процессе занятий представлено в таблице № 3

В отличие от предыдущих случаев, здесь до начала эксперимента ситуация несколько иная в разных группах. Контрольная группа в целом выглядит более уравновешенной, показывая только 12,3 \% обучающихся с заниженным уровнем. При этом в экспериментальной группе заниженный уровень выявлен у $16 \%$ обучающихся, адекватный - 58,1\% (в контрольной - 62, 9\%), завышений имеют практически равное количество обучающихся. После окончания эксперимента данные в контрольной группе не значительно отличаются, хотя ожидаемо наблюдается рост адекватного и завышенного уровня и снижение заниженного. Совершенно по-другому обстоят дела в экспериментальной группе. После проведения эксперимента только 7 \% обучающихся показали заниженный уровень, подавляющее большинство (83,1 \%) - адекватный уровень. Стоит отметить резкое снижение обучающихся с завышенным уровнем.

Уровень личностной тревожности у обучающихся представлен в таблицу №4

Значительные отклонения от уровня адекватной тревожности требуют особого внимания. Высокая тревожность предполагает склонность к появлению тревоги у обучающихся СМГ в ситуациях оценки компетентности.
В этом случае следует снизить значимость ситуации и задач и перенести акцент на осмысление деятельности и формировать чувство уверенности в успехе. А низкая тревожность, наоборот, требует повышения внимания к деятельности и к чувствам ответственности и уверенности.

Результаты тестирования по самооценке личности представлены в таблице №5

Завышенный, так же как и заниженный уровень самооценки личности может быть следствием самых разных причин и не должен пугать человека. Дело не в том, что люди, чрезмерно высоко или чрезмерно низко оценившие себя, нуждаются в специальной психологической помощи, они же живут в семье, в учатся коллективе и это не может не накладывать отпечаток. Как показывает опыт, что для коллектива, его социально-психологического климата, одинаково плохо наличие в нем людей, неадекватно оценивающих себя.

\section{Выводы}

Вследствие, проведенного нами эксперимента по исследованию самооценки личности обучающихся СМГ в процессе занятий физической культурой в вузе выявили, что использование разработанной нами программы, где содержание и организация учебно-воспитательного процесса по физическому воспитанию обусловлены вырабатыванием адекватной самооценки личности, комплексное развитие всех физических качеств и профилактические действия, направленные на устранение незначительных отклонений ОДА, а также адаптацию организма к постепенно повышающейся физической нагрузке и улучшило результаты по многим показателям на достоверном уровне.

Повышение общего числа обучающихся с адекватным уровнем самооценки и уменьшение их с заниженным уровнем, связано тем, что умение объективно оценивать свои возможности правильного выполнения конкретных двигательных действий наряду с умением сопоставлять достигнутые результаты с требованиями являются неотъемлемым условием полноценного и качественного усвоения программы по физическому воспитанию в вузе. Характер изменений в контрольной группе можно назвать вероятностным, потому что в нем присутствуют как положительные, так и отрицательные тенденции.

Предоставленные педагогические условия влияния на формирование и коррекцию самооценки личности обучающихся СМГ в процессе занятий по дисциплинам «Физическая культура и спорт» и «Элективные дисциплины по физической культуре и спорту», бесспорно, оказывают позитивное влияние на повышение уровня не только адекватной самооценки, но и общей физической подготовленности обучающихся СМГ. 


\section{ЛИТЕРАТУРА}

1. Ахмерова, С.Г. Здоровый образ жизни и его формирование в процессе обучения / С.Г. Ахмерова // Профилактика заболеваний и укрепление здоровья. 2001. - № 2. - C. 37-40.

2. Бароненко, В.А. Здоровье и физическая культура студента : учебное пособие / В.А. Бароненко, Л.А. Рапопорт. - М. : Альфа, 2003. - 351 с. : ил

3. Брег, П.С. Позвоночник - ключ к здоровью / П.С. Брэгг, С.П. Махешварананда, Р. Нордемар. - СПб. : 000 «Диамант», 2001. - 512 с. : ил.

4. Голомолзина, В.П. Влияние нагрузок различной направленности на физическое состояние и заболеваемость студенток специальной медицинской группы / В.П. Голомолзина, С.П. Левушкин // Ученые записки университета им. П.Ф. Лесгафта. -2008. - № 6 (40). - С. 24-28.

5. Забалуева, Т.В. Профилактика и коррекция нарушений осанки школьников на занятиях различными видами спорта / Т.В. Забалуева // Ученые записки университета им. П.Ф. Лесгафта. - 2007. - № 9 (31). - С. $41-45$.

6. Захарова, А.В. Генезис самооценки / А.В. Захарова. - Тула : Изд-во Тульского гос. пед. ун-та им. Л.Н. Толстого, 1998. - 135 с.

7. Мак-Кензи, Р.Т. Физические упражнения в воспитании и медицине: извлечения. Сколиозы и их лечение / Р.Т. Мак-Кензи // ЛФК и массаж. Спортивная медицина. -2007 . - № 8. - С. 39-50.

8. Милюкова, И.В. Лечебная физкультура. Новейший справочник / И.В. Милюкова, Т.А. Евдокимова; под общей ред. проф. Т.А. Евдокимовой. - СПб. : Сова; М.: Изд-во «ЭКсмо», 2003. - 862 с. : ил.

9. Куликова М.Г., Лебедева Е.Г.. Исследование отношения студентов специальной медицинской группы к своему здоровью/ Куликова М.Г., Лебедева Е.Г.// Рецензируемый научный журнал «Тенденции развития науки и образования». Февраль 2019г. № 47, Часть 1 Изд. НИЦ «Л-Журнал», 2019. - 88с.

10. Тимошина, И.Н. Показания и противопоказания по содержанию занятий по физической культуре в специальной медицинской группе / И.Н. Тимошина // Физическая культура. - 2007. - № 4. - С. 65-68.

11. Хомутов, Г.А. Адаптивная физическая культура в профессиональной подготовке студентов высшего учебного заведения : дис. ... канд. пед. наук / Хомутов Г.А. -СПб., 1999. -242 с.

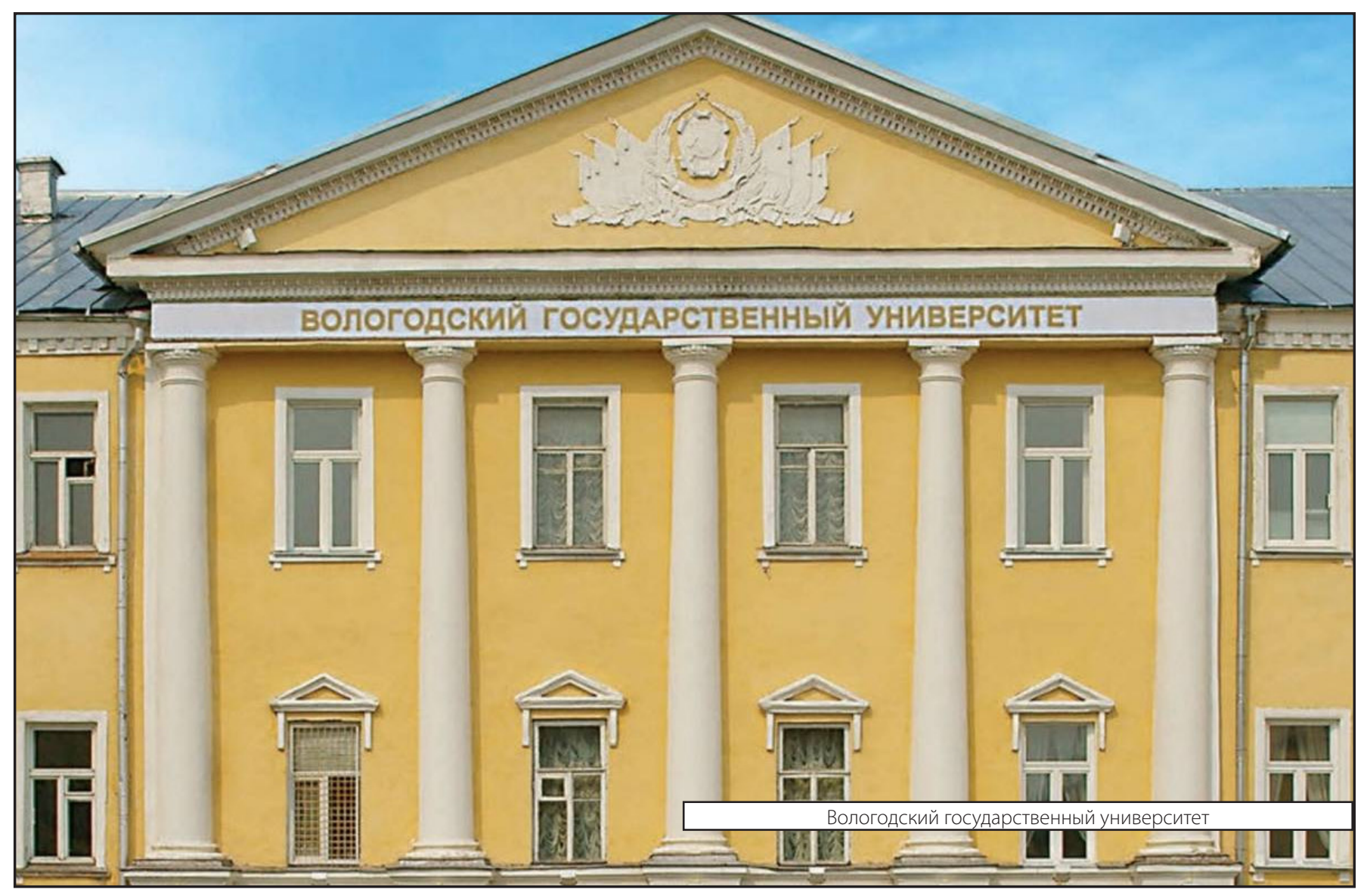

